\title{
Different Pasts for Different Political Folk: Political Orientation Predicts Collective Nostalgia Content
}

\author{
Anna Stefaniak ${ }^{1}$, Michael Jeremy Adam Wohl ${ }^{1 *}$, Constantine Sedikides ${ }^{2}$, Anouk Smeekes $^{3}$ \\ and Tim Wildschut ${ }^{2}$
}

${ }^{1}$ Department of Psychology, Carleton University, Ottawa, ON, Canada, ${ }^{2}$ School of Psychology, University of Southampton, Southampton, United Kingdom, ${ }^{3} E R C O M E R$, Utrecht University, Utrecht, Netherlands

OPEN ACCESS

Edited by:

Philip Gordon Chen,

Beloit College, Beloit, WI,

United States

Reviewed by:

Susan Banducci,

University of Exeter, United Kingdom

Diego Fossati,

City University of Hong Kong,

Hong Kong

${ }^{*}$ Correspondence:

Michael Jeremy Adam Wohl

Michael.wohl@carleton.ca

Specialty section:

This article was submitted to Elections and Representation, a section of the journal

Frontiers in Political Science

Received: 25 November 2020

Accepted: 05 February 2021

Published: 29 March 2021

Citation:

Stefaniak A, Wohl MJA, Sedikides C, Smeekes A and Wildschut T (2021) Different Pasts for Different Political

Folk: Political Orientation Predicts

Collective Nostalgia Content.

Front. Polit. Sci. 3:633688.

doi: $10.3389 /$ fpos.2021.633688
Collective nostalgia is a bittersweet emotion that reflects sentimental longing for valued aspects of the past of one's group. Given that conservatism is typically associated with a general desire to preserve the societal status quo or return society to its traditional way of being, nostalgia has been theorized to be characteristic of those on the political right (i.e., conservatives). In the current work, we proposed and tested the hypothesis that collective nostalgia is experienced by both conservatives and liberals, but the content of their nostalgizing differs. Across three studies in three socio-political contexts-United States (Study 1, MTurk, $N=352$ ), Canada (Study 2, student sample, $N=154$ ), and England (Study 3, online panel, $N=2,345$ )-we found that both conservatives and liberals experienced collective nostalgia for a more homogenous and open society. However, conservatives experienced more homogeneity-focused collective nostalgia, whereas liberals experienced more openness-focused collective nostalgia. Replicating previous findings, homogeneity-focused nostalgia emerged as a positive, whereas openness-focused nostalgia emerged as a negative, predictor of intergroup attitudes. The results have both theoretical and practical significance for understanding political attitudes and behaviors. To the point, variance in the conservative and liberal political agendas is, in part, a function of a difference in their respective predisposition to nostalgize about and thus desire the return of a particular aspect of the in-group's past.

Keywords: collective nostalgia, political orientation, openness-focused nostalgia, homogeneity-focused nostalgia, intergroup attitudes

\section{INTRODUCTION}

As humanity fumbles toward modernity, a sense of loss and change have grown in many societies (Duyvendak, 2011). That is, some people feel that a cherished social group to which they belong (their ingroup) is losing connection with its past (Smeekes and Verkuyten, 2015). Such a feeling of collective discontinuity (i.e., disconnection) is aversive. People prefer to believe that their social groups have temporal persistence (i.e., collective continuity; Sani, 2010), because the past provides the existential ground on which group members stand (Jetten and Wohl, 2012). Put differently, the past informs group members who they are, where they came from, and where they are going. As such, when group members come to believe that their group is becoming discontinuous, they often turn back to the past, as it provides an anchor in the midst of uncertainty (Wohl et al., 2020a). This is 
typically accomplished psychologically via collective nostalgic reverie (i.e., wistful reflection) - a group-based emotion that helps bridge the past with the present (Wildschut et al., 2014; Sedikides and Wildschut, 2019; Wohl et al., 2020b). By reliving the past through collective nostalgia, the group member symbolically rekindles bonds with the ingroup's past, a process that can confer psychological equanimity.

Indeed, the human mind is a master time traveler, with the past often being a place of refuge for people who perceive that a cherished group to which they belong (e.g., national, religious) is under threat. Group members experiencing collective nostalgia turn to the past to find (or construct) the source of their social identity, agency, and community that are felt to be blocked, subverted, or threatened in the present. Collective nostalgia can thus be framed as a coping mechanism. Nostalgizing about better times in the group's past directs group members' focus to what aspects of their group help define the essence of the group, and thus what to protect in the name of ensuring the ingroup's future (Wohl et al., 2020a). In this way, collective nostalgia is functional. It motivates group members not only to take pro-ingroup action, but also directs what action is needed to ensure collective continuity (Wohl et al., 2020b; Cheung et al., 2020).

Within the political sphere, nostalgic rhetoric represents a call for collective continuity in times of perceived insecurity and social change. Specifically, nostalgia is often used as a tool to justify and support policies and political stances that aim to reestablish connection with the group's fundamental essence-an essence that is threatened by different aspects of modernity (e.g., immigration; Robinson, 2016). As such, nostalgia is often thought to be an intrinsically conservative emotion (Schlesinger, 1955; Kenny, 2017; Lammers \& Baldwin, 2018). This is so, because the politics of conservatism are typically linked to an overvaluation of the past and a corresponding need to keep things the way they were (Kirk, 1953; Muller, 1997).

Herein, we contend that the traditional approach to collective nostalgia (i.e., collective nostalgia as a conservative emotion) conflates longing for the past with longing for a stable, traditional, and hierarchized society. That is, collective nostalgia can and does have utility on both sides of the political spectrum. As argued by Kenny (2017) and Mudde (2017), nostalgic rhetoric is a widespread tool of political discourse-one that is used by conservatives and liberals alike. Liberals, for example, are defined, in part, by their openness to experience and rejection of inequality (Jost et al., 2003). They may be confronted, then, by socio-political contexts which elicit the belief that the present is unstable and shifts the group away from the values of openness and equality. Consequently, they may long to return to a past when (in their mind's eye) group members were more open to others, their ideas, and their way of life (i.e., liberal-oriented nostalgizing; Wohl et al., 2020b). In all, we hypothesized that both conservatives and liberals engage in collective nostalgia, but the content of their nostalgic reverie differs. Whereas conservatives are apt to nostalgize about days of yore in which the ingroup was more homogeneous, liberals are apt to nostalgize about days where the ingroup was more open to other cultures and their way of life. To test this hypothesis, we conducted three studies in three socio-political contexts: United States, Canada, and England.

\section{Nostalgic Reverie as Conservatism}

In the opening sentence of his 2018 article on polarization in America, Tom Jacobs wrote: "In these polarized times, liberals and conservatives tend to talk past each other. Leftists tend to envision a brighter future, while right-wingers lovingly look to a more-perfect past. 'Forward,' urged Barack Obama. 'Make America Great Again,' replied Donald Trump”. With this observation, Jacobs, 2018 captures a critical difference between conservatives and liberals: conservatives tend to be past-focused, while liberals tend to be future-focused. Indeed, since the French Revolution, an ideological fault line exists that separates people who have a relative preference for the status quo and how things were traditionally done (conservatives) from those who have a relative preference for change and how things could be (liberals; Jost et al., 2008).

The conservative preference for how things used to be means that, in the modern world, rapid social and political changes may be perceived as a threat to their cherished social groups (e.g., national or religious)-groups that are seen as becoming untethered from what they really are as a result of societal change (Duyvendak, 2011). One way to alleviate this threat is by turning to the past and finding refuge in the "good old days." Collective nostalgia, a sentimental longing for the past of one's group (Wildschut et al., 2014; Wohl and Stefaniak, 2020), allows people to focus on the aspects of their group that are of import and worth protecting in the name of ensuring the group's future vitality. Given conservatives' general preference for tradition and

TABLE 1 | Means, standard deviations, correlations among variables, and comparisons between liberals and conservatives study 1.

\begin{tabular}{|c|c|c|c|c|c|c|c|c|}
\hline & \multicolumn{2}{|c|}{ M (SD) } & \multirow[t]{2}{*}{$F_{\text {int }} / t$} & \multirow[t]{2}{*}{$\eta_{p}^{2} / d$} & \multirow[t]{2}{*}{1.} & \multirow[t]{2}{*}{2.} & \multirow[t]{2}{*}{3.} & \multirow[t]{2}{*}{4.} \\
\hline & Conservative & Liberal & & & & & & \\
\hline 1. CN-homogeneity & $4.19^{\mathrm{a}}(1.27)$ & $2.92(1.56)$ & $87.98^{\star \star \star}$ & 0.25 & & $-0.174^{\star}$ & $-0.262^{* *}$ & $0.348^{* \star \star}$ \\
\hline 2. CN-openness & $4.52^{\mathrm{a}}(1.22)$ & $5.57(1.28)$ & & & -0.142 & & $0.420^{\star \star \star}$ & $-0.472^{* \star \star}$ \\
\hline 3. Feelings & $9.41(21.68)$ & $27.74(20.01)$ & $7.24^{\star \star \star}$ & -0.88 & $-0.181^{\star}$ & $0.170^{\star}$ & & $-0.731^{\star \star \star}$ \\
\hline 4. Social distance & $2.52(0.94)$ & $1.67(0.78)$ & $-8.12^{\star \star \star}$ & 0.99 & $0.350^{\star \star \star}$ & $-0.232^{\star \star}$ & $-0.659^{\star \star \star}$ & \\
\hline
\end{tabular}

CN-homogeneity, homogeneity-focused collective nostalgia; CN-openness, Openness-focused collective nostalgia; Feelings, Feeling thermometer towards outgroups. We calculated the comparison between levels of the two types of collective nostalgia between conservatives and liberals using mixed-design Analysis of Variance (ANOVA) ( $F_{\text {int }}=$ interaction term), and calculated the comparison for levels of feelings towards outgroups and social distance using independent sample t-test. Means with the same superscript do not differ from one another. Correlations above the diagonal are for conservatives, below for liberals.

${ }^{* * *} p<0.001,{ }^{* *} p<0.01,{ }^{*} p<0.05$. 
the status quo, they are perceived as significantly more susceptible to experiencing collective nostalgia than liberals (Mudde, 2016; Robinson, 2016; Kenny, 2017). Providing empirical support for this supposition, Lammers and Baldwin (2018), Study 1 showed that conservatives are more prone to nostalgizing about the past than are liberals. In fact, these authors showed that simply framing liberal issues (e.g., gun control, support for immigration) as "going back to how things were" (vs. as a future-oriented progress) was enough to garner support of conservative participants or at least substantially decrease their opposition. Stronger collective nostalgia is also significantly and positively associated with political conservatism (Smeekes and Verkuyten, 2015, Studies 1-3; Smeekes et al., 2015, Studies 1 and 2).

The powerful impact of collective nostalgic reverie on the political scene was evidenced by the successes of the 2016 Republican (i.e., conservative) presidential candidate Donald Trump as well as the 2016 "Leave" campaign led by the Conservative Party in the United Kingdom in their desire to exit from the European Union (i.e., BREXIT). By skillfully appealing to nostalgic sentiments, Trump was able to convince enough Americans to elect him President of the United States in 2016, and the Conservative Party was able to convince enough voters to support them and their BREXIT initiative. Thus, both existing research and salient political outcomes suggest that collective nostalgia is, in fact, an emotion that is not only conservative in nature, but that when experienced can breed conservatism. Contrary to this perspective, we contend that traditional understanding of the link between collective nostalgia and political ideology has overlooked one crucial component-the content of collective nostalgia, that is, the exact elements of collective past for which people are nostalgic (Wohl et al., 2020a; Wohl et al., 2020b). Specifically, we argue that it is not simply that conservatives experience nostalgia and liberals do not (or do so to a disproportionately lesser extent). Instead, people who differ in their political orientation will likely experience different types of nostalgia. To the point, politicians on opposite ends of the ideological spectrum use nostalgia to garner support, but appeal to different elements of the past.

Indeed, calls to make America great again and to get Britain back could be understood as appealing to times when traditionally dominant social groups (White men) had greater power in society and were not threatened by immigration and demands for equal rights from minorities (Mudde, 2017; Gaston and Hilhorst, 2018). At the other end of the political spectrum, Barack Obama invoked America's "founding principles" and its history as an immigrant nation to support his plea for immigration reform (Remarks by the President on Comprehensive Immigration Reform, 2013). Similarly, United States senator Bernie Sanders refers to the secure, wellpaying blue-collar jobs of the 1950's, and to stronger trade unions and welfare state of the past, to argue for the need of similar institutions and protections today (Mudde, 2018). Taken together, politicians on both ends of the ideological divide appear to use collective nostalgia (albeit for different elements of the past) to mobilize their voters.

\section{Collective Nostalgia Contents}

Nostalgia refers to sentimental longing for the past (Sedikides et al., 2004). Initially, it was studied as an individual-level medical condition (Anspach, 1934) and later as a psychiatric disorder (Sedikides et al., 2004). Since then it has lost its purely negative and medical connotation, and is now commonly understood as an emotion that is predominantly positive (as it entails longing for positively valenced past) with an element of bitterness (because that past is now gone) (Sedikides and Wildschut, 2016; Leunissen et al., 2020; Wohl and Stefaniak, 2020). Recent research shows that people may and do experience nostalgia not only for their personal past, but also as a function of their group belonging (Wildschut et al., 2014; Sedikides and Wildschut, 2019). Similar to its individual-level counterpart, collective nostalgia entails longing for a time in the past of one's social group that is seen as particularly illustrious.

Understood in this way, collective nostalgia has been seen as more characteristic of conservatives (Robinson, 2016; Kenny, 2017). However, this may be an artifact of traditional understanding and operationalization of the concept. In most extant research, collective nostalgia was treated as a unitary phenomenon. That is, participants were asked about the extent to which they experienced collective nostalgia, but not about the specific aspects of the collective past for which they felt nostalgic. For instance, Wildschut et al. (2014) asked their participants to think about a nostalgic event that they experienced alone or with other people in their social group, and then to rate the extent to which they were "having nostalgic feelings" and they were "feel [ing] nostalgic at the moment" (Wildschut et al., 2014, Study 1 and Study 2). Similarly, Smeekes (2015; see also Smeekes et al., 2015) asked Dutch participants whether they felt nostalgic for " $\mathrm{t}]$ he way Dutch people were," "[t]he way Dutch society was," and "[t]he way the Dutch landscape (i.e., surroundings) looked like," and found a significant positive correlation with conservatism. Lammers and Baldwin (2018) assessed participants' nostalgia proneness with Holbrook, 1993 8-item scale (e.g., "Things used to be better in the good old days," "They don't make 'em like they used to"). Given conservatives general preference for the past, it is not surprising that they scored higher than liberals.

However, considering that the aspects of the collective past called upon by left and right-wing politicians are diametrically opposed, it is possible that the extant measures of nostalgia simply did not capture liberal nostalgia. Mudde and Kaltwasser (2018) in their work on populism contended that, if collective nostalgia, typically attributed to the populist right, were operationalized in a way that captured more "socialist" aspects of the past, populist left may relate to it just as strongly as populist right does. Some support for this contention comes from three studies reported by Lammers and Baldwin (2020). They showed that, when collective nostalgia was differentiated into nostalgia for less vs. more political correctness, nostalgia for less political correctness was positively associated with right-wing populism, whereas nostalgia for more political correctness was negatively associated with right-wing populism. However, to our knowledge, no research exists that directly compares the types of collective nostalgia experienced by liberals and conservatives or the relative levels of collective nostalgia among them. 
We conducted the current research to fill the aforementioned gap in knowledge. We employed a more nuanced approach to the collective nostalgia that liberals compared to conservatives are likely to experience. Specifically, we explored collective nostalgia among self-identified liberals and conservatives for elements of the collective past that are potentially more appealing to people on the left and right side of the political spectrum. Reflecting conservatives' preference for tradition and acceptance of inequality (Jost et al., 2008), we assessed nostalgia for a more ethnically homogeneous society of the past. Reflecting liberals' preference for equality, we assessed collective nostalgia for a more open and tolerant society of the past. We also investigated the potential role of different types of collective nostalgia in explaining the link between political orientation and intergroup attitudes (Duckitt, 2001; Jost et al., 2008). In prior research, collective nostalgia for a homogenous society predicted more hostile intergroup attitudes, whereas collective nostalgia for an open society predicted more positive intergroup attitudes (Wohl et al., 2020b). Therefore we hypothesized that one of the outcomes of participants orientation as conservative (compared to liberal) would be their relative preference for homogeneity-focused nostalgia and disfavor towards opennessfocused nostalgia. In turn, this preference would explain conservatives relatively less favorable intergroup attitudes (towards minorities and towards immigrants) and desire to maintain social distance from outgroup members. We tested this hypothesis in three studies conducted in the United States, Canada, and England. For all studies, we received ethical approval from the Carleton University Office of Research Ethics.

\section{METHODS AND MATERIALS}

\section{Study 1 \\ Method}

In Study 1, a correlational investigation, we tested a sample of United States MTurk workers. Study overview and data are available at OSF: https://osf.io/vutyq/

\section{Participants}

Out of $N=391$ MTurk workers who clicked on the survey link, one person did not answer any questions, 22 people failed one of the pre-specified qualifiers (i.e., they declared not being Christian), 15 people withdrew from the study, and one person indicated that they did not consent to their data being used upon being debriefed. The final sample comprised 352 participants. ${ }^{1}$ The participants were on average 34.55 years old $(S D=11.86)$. Of them, $188(53.41 \%)$ identified as female, 163 $(46.31 \%)$ as male, and one person $(0.28 \%)$ as genderqueer.

\footnotetext{
${ }^{1}$ A sensitivity power analysis showed that the study was sufficiently powered to detect the hypothesized interaction of political orientation and type of collective nostalgia (achieved power $=0.84$ ), as well as the hypothesized mediation effects (all achieved power $=1.00$ ).
}

\section{Measures $^{2}$}

Unless otherwise indicated all measures used a response scale from 1 (strongly disagree) to 7 (strongly agree).

We assessed political orientation with a single item: "In politics people refer to the political Left (i.e., liberal) and Right (i.e., conservative). Where would you place yourself on the following scale?" Participants could select one of the following answers: strongly liberal, somewhat liberal, in between, somewhat conservative, strongly conservative, don't know/other. Given that we were only interested in analyzing data from participants with a clear ideological preference, we excluded those who selected in between and don't know/other, and created a new binary variable that captured the liberal (strongly and moderately identified, $n=139$ ) vs. conservative (strongly or moderately identified, $n=132$ ) division.

We measured collective nostalgia with three items that tapped into homogeneity-focused collective nostalgia (e.g., "I long for a time when Americans were more culturally similar"), and three items that tapped into openness-focused collective nostalgia (e.g., "I feel nostalgic for a time when America was more open to cultural diversity"), all taken from Wohl et al. (2020b). We then calculated the composite scores for each type of nostalgia $(\alpha=$ 0.68 for homogeneity-focused nostalgia, $\alpha=0.69$ for opennessfocused nostalgia).

We used two indicators of intergroup attitudes: feeling thermometer and social distance. The feeling thermometer measure asked the participants about their feelings towards Muslims, Jews, and refugees. ${ }^{3}$ The response scale ranged from -50 (cold/negative) to +50 (warm/positive). The three items were strongly inter-correlated, and so we averaged them to create an index of intergroup feelings $(\alpha=0.83)$. The social distance measure assessed whether participants would accept the presence of outgroup members in their social circles (modeled on Bilewicz et al., 2013). The measure asked about the extent to which participants would be comfortable if a Jew/Muslim/refugee became their boss, moved into their neighborhood, or married a member of their family. The response scale ranged from $1=$ very uncomfortable to $5=$ very comfortable, but was re-coded such that higher scores indicated greater social distance. We averaged the items to create a global social distance index $(\alpha=0.94)$.

\section{Results}

We present, in Table 1, means, standard deviations, and correlations among variables as well as differences between liberals and conservatives on all variables.

Replicating effects observed by Wohl et al. (2020b), homogeneity-focused nostalgia was positively related to social distance and negatively related to warm feelings towards outgroups, whereas openness-focused nostalgia showed an opposite results pattern. The two types of nostalgia were

\footnotetext{
${ }^{2}$ See Supplementary Material for the exact wording of all measures used in all three studies.

${ }^{3} \mathrm{We}$ also asked about attitudes towards gay people. However, given that we did not record participants sexual orientation, it was impossible to determine whether, for a given participant, gay people were an ingroup or an outgroup. Therefore, we did not analyze the relevant data.
} 

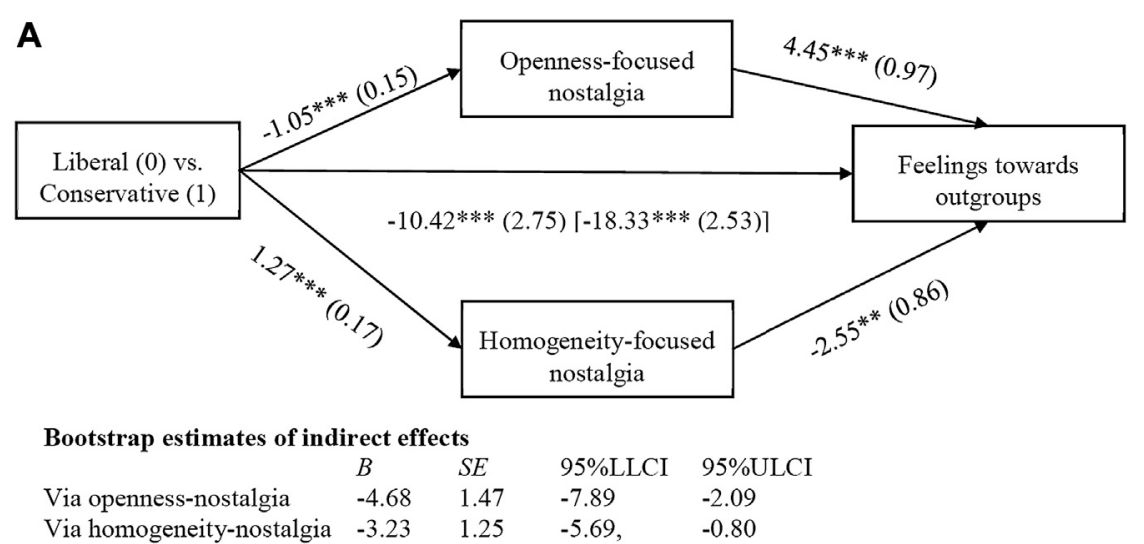

B

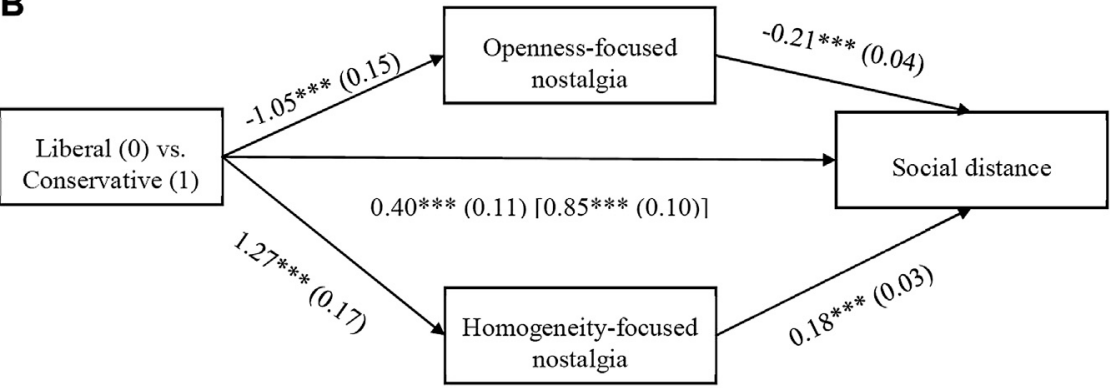

Bootstrap estimates of indirect effects

$\begin{array}{lllll} & B & S E & 95 \% \mathrm{LLCI} & 95 \% \mathrm{ULCI} \\ \text { Via openness-nostalgia } & 0.22 & 0.06 & 0.13 & 0.34 \\ \text { Via homogeneity-nostalgia } & 0.23 & 0.05 & 0.13 & 0.33\end{array}$

FIGURE 1 | Mediation of the effect of participants' political orientation on (A) feelings towards outgroups and (B) social distance towards outgroups in study 1 (American participants, MTurk). Unstandradized coefficients are presented, total effects is in square brackets.

significantly negatively associated among conservatives, but only descriptively negatively associated among liberals. We found a significant interaction between participants' political orientation and the type of collective nostalgia they reported, $F(1,269)=$ $87.98, p<0.001, \eta_{\mathrm{p}}{ }^{2}=0.25$. Among liberals, the level of opennessfocused nostalgia was significantly higher than their level of homogeneity-focused nostalgia $\left(p<0.001, \eta_{\mathrm{p}}{ }^{2}=0.47\right)$. Conservatives reported similar levels of both types of collective nostalgia $\left(p=0.069, \eta_{\mathrm{p}}{ }^{2}=0.01\right)$. Liberals reported significantly more openness-focused nostalgia than conservatives $(p<0.001$, $\eta_{\mathrm{p}}{ }^{2}=0.15$ ), while conservatives reported significantly more homogeneity-focused nostalgia than liberals $\left(p<0.001, \eta_{\mathrm{p}}{ }^{2}=\right.$ $0.17)$. Overall, conservatives were not more nostalgic than liberals, $F(1,269)=1.06, p=0.305, \eta_{\mathrm{p}}{ }^{2}=0.004$.

Next, we conducted two mediation analyses (Process 3.0, Model 4; Hayes, 2017) in which we entered participants' political orientation as the independent variable, two types of collective nostalgia as mediators, and feelings towards outgroups and social distance as separate dependent variables. Conservatives experienced significantly less openness-focused nostalgia, $B=-1.05, S E=0.15,95 \% \mathrm{CI}[-1.35,-0.75]$, and more homogeneity-focused nostalgia, $B=1.26, S E=0.17,95 \%$ CI $[0.93,1.61]$, than liberals. The two types of nostalgia, in turn, were related to more positive, $B=4.45, S E=0.97,95 \%$ CI $[2.53$,
6.37], and more negative, $B=-2.55, S E=0.85,95 \% \mathrm{CI}[-4.23$, -0.87 ], feelings towards outgroups, respectively. Identifying as a conservative (compared to identifying as a liberal) had a negative indirect effect on intergroup feelings via less openness-focused nostalgia, $B=-4.68, S E=1.47,95 \% \mathrm{CI}[-7.89,-2.09]$, and via more homogeneity-focused nostalgia, $B=-3.23$, $S E=1.25$, $95 \%$ CI $[-5.69,-0.80]$ (Figure 1A).

When the model tested social distance as the dependent variable (Figure 1B), the relations between participants' political orientation and the two types of collective nostalgia were identical. Opennessfocused collective nostalgia related to a desire for less social distance towards outgroups, $B=-0.21, S E=0.04,95 \% \mathrm{CI}[-0.29,-0.14]$, and homogeneity-focused collective nostalgia was related to a desire for more social distance towards outgroups, $B=0.18, S E=0.03,95 \% \mathrm{CI}$ $[0.11,0.24]$. The effect of participants conservative political orientation on the desire for more social distance towards outgroup was mediated via both homogeneity-focused nostalgia, $B=0.23, S E=0.05,95 \% \mathrm{CI}[0.13,0.33]$, and openness-focused nostalgia, $B=0.22$, $S E=0.06,95 \% \mathrm{CI}[0.13,0.34]$.

\section{Discussion}

We demonstrated in Study 1 that participants who identify (strongly or moderately) as conservatives and liberals differ in the type and intensity of collective nostalgia that they experience. 
Although conservatives experienced significantly more homogeneity-focused nostalgia than liberals, liberals experienced significantly more openness-focused nostalgia than conservatives. These differences in the content of collective nostalgia were, in turn, related to participants' intergroup attitudes. Specifically, the greater intergroup hostility (evidenced by more negative feelings and greater social distance towards outgroups) reported by conservatives was partly explained by the higher degree of homogeneity-focused nostalgia and lower degree of openness-focused nostalgia they experienced compared to liberal participants.

\section{Study 2 \\ Method}

In Study 1, we obtained support for our hypothesis that conservatives and liberals nostalgize about different aspects of their group's past. In Study 2, we sought to replicate and extend these findings to a different national context. Specifically, we wondered whether we could find a similar pattern of results among young adults and verify whether different types of collective nostalgia would explain the link between participants political orientation and anti-immigration sentiments. To this effect, we included measures of interest in a longitudinal study that was a part of a larger project on the influence of changes in the political context (namely, parliamentary elections) on collective nostalgia in Canada ${ }^{4}$. Data are available at OSF: https://osf.io/vga8c/

\section{Participants}

We intended to recruit a sample of 300 Canadian students from a university in Ontario. However, despite our efforts to encourage participation, only 162 students clicked on the survey link at Time 1. Of those, three indicated that the were not Canadian citizens, four did not identify as Canadian, and one indicated that they were not yet 18 years old. We excluded these individuals, leaving a sample of $154 .{ }^{5}$ Participants were on average 20.95 years old (SD $=7.33)$. Of them, 101 (65.58\%) identified as female, 46 (29.87\%) as male, and $1(0.65 \%)$ as trans male, with six (3.9\%) not indicating gender.

\section{Measures}

Unless otherwise indicated, all measures implemented a response scale from 1 (strongly disagree) to 7 (strongly agree). ${ }^{6}$

\footnotetext{
${ }^{4}$ Therefore, we only report results obtained in the first study wave. Please note that there were no differences between participants who took part in the study at Time 1 and Time 2 and the pattern of results held whether Time 1 or Time 2 results were analyzed.

${ }^{5} \mathrm{~A}$ sensitivity power analysis revealed that the study was sufficiently powered to detect the hypothesized interaction between political orientation and type of collective nostalgia (achieved power $=0.81$ ), but was underpowered to detect the mediation effects. Specifically, the study achieved 0.07 power to detect mediation via homogeneity-focused collective nostalgia and 0.57 power to detect the effect via openness-focused collective nostalgia in the model for intergroup feelings, and 0.27 and 0.05 , respectively, in the model for antiimmigration sentiments.

${ }^{6}$ As indicated, Study 2 was a part of a larger research project. Thus, besides measures reported here, this project included measures of voting preferences and voting behavior, essentialist perceptions of political figures, and collective angst.
}

We assessed political orientation with the same single item as in Study 1. Again, given our interest in the attitudes of conservatives vs. liberals, we excluded participants who selected in between and don't know/other as their political preference from analyses. We also created a binary variable that captured the split between conservative $(n=19)$ and liberal $(n=76)$. The sample was predominantly liberal, given the general liberal skew of the Canadian population, which is even stronger in university students (Hastie, 2007; 2020 Social Progress Index Executive Summary, 2020).

We measured collective nostalgia with two items tapping into homogeneity-focused nostalgia, $r(93)=0.806, p<0.001$, and two items tapping into openness-focused nostalgia, $r(93)=0.660, p<$ 0.001 . We derived these items from Wohl et al. (2020b) and adjusted them to the Canadian context. We calculated composite scores for each type of nostalgia.

We used two indicators of intergroup attitudes: feeling thermometer and anti-immigration sentiments. Feeling thermometer asked the participants about the extent to which their feelings towards Muslims, refugees, Indians, Africans, and Chinese were cold/negative $(-50)$ or warm/positive $(+50)$. The five items were strongly inter-correlated and so we averaged them to form an index of intergroup feelings $(\alpha=0.94)$. We measured anti-immigration sentiments with a single item: "You will now receive a question about the number of immigrants that the Canadian government allows access to Canada. Please indicate whether you find these numbers too little, good, or too much. The number of immigrants the Canadian government is allowing into our country is: ..." The response scale ranged from 1 (way too little) to 5 (way too many).

\section{Results}

We followed the same data-analytic strategy as in Study 1. We display, in Table 2, means, standard deviations, correlations among variables, and differences between conservatives and liberals on the measured variables. Likely due to the much smaller sample size, most of bivariate correlations were not significant. However, we did find a significant positive correlation between openness-focused nostalgia and warm intergroup feelings among liberals.

Comparisons between conservatives and liberals showed that, as hypothesized, the former had more negative intergroup feelings and stronger anti-immigration sentiments. Again, there was a significant interaction between participants' political orientation and the type of collective nostalgia they reported, $F(1,93)=21.50, p<.001, \eta_{\mathrm{p}}{ }^{2}=0.19$. Conservatives experienced similar levels of homogeneity-focused nostalgia and openness-focused nostalgia $\left(p=0.909, \eta_{\mathrm{p}}{ }^{2}=0.0001\right)$. Liberals reported significantly stronger openness-focused nostalgia than homogeneity-focused nostalgia $\left(p<0.001, \eta_{\mathrm{p}}^{2}=0.53\right)$. Liberals experienced marginally more openness-focused nostalgia than conservatives $\left(p=0.083, \eta_{\mathrm{p}}{ }^{2}=0.03\right)$, whereas conservatives experienced significantly more homogeneity-focused nostalgia, compared to that of liberals $\left(p<0.001, \eta_{p}{ }^{2}=0.17\right)$. The main effect of political orientation on collective nostalgia was significant such that conservatives reported more nostalgia than liberals, $F(1,50)=8.66, p=0.005, \eta_{\mathrm{p}}{ }^{2}=0.15$. 
TABLE 2 | Means, standard deviations, correlations among variables, and comparisons between liberals and conservatives study 2.

\begin{tabular}{|c|c|c|c|c|c|c|c|c|}
\hline & \multicolumn{2}{|c|}{$M(S D)$} & \multirow[t]{2}{*}{$F_{\text {int }} / t$} & \multirow[t]{2}{*}{$\eta_{p}^{2} / d$} & \multirow[t]{2}{*}{1.} & \multirow[t]{2}{*}{2.} & \multirow[t]{2}{*}{3.} & \multirow[t]{2}{*}{4.} \\
\hline & Conservative & Liberal & & & & & & \\
\hline 1. CN-homogeneity & $4.13^{\mathrm{a}}(1.46)$ & $2.39(1.57)$ & $21.50^{\star \star \star}$ & 0.19 & & -0.100 & -0.070 & 0.312 \\
\hline 2. CN-openness & $4.08^{a, \dagger}(1.30)$ & $4.70^{\mathrm{b}}(1.41)$ & & & 0.125 & & -0.078 & -0.109 \\
\hline 3. Feelings & $5.80(20.39)$ & $36.37(17.21)$ & $6.01^{\star \star \star}$ & -1.71 & -0.166 & $0.254^{\star}$ & & -0.452 \\
\hline 4. Anti-immigration & $3.79(0.86)$ & $2.79(0.68)$ & $-5.44^{\star \star \star}$ & 1.39 & 0.202 & -0.080 & $-0.390^{* \star}$ & \\
\hline
\end{tabular}

CN-homogeneity,homogeneity-focused collective nostalgia; CN-openness, Openness-focused collective nostalgia; Feelings, Feeling thermometer towards outgroups; Anti-immigration, anti-immigration sentiments. We calculated the comparison between levels of the two types of collective nostalgia between conservatives and liberals using mixed-design Analysis of Variance (ANOVA) ( $F_{\text {int }}=$ interaction term), and calculated the comparison for levels of feelings towards outgroups and social distance using independent sample $\mathrm{t}$-test. Means with the same superscript do not differ from one another (or differ only marginally, when indicated by: ${ }^{\dagger}$ ). Correlations above the diagonal are for conservatives, below for liberals.

${ }^{* * *} p<0.001,{ }^{* *} p<0.01,{ }^{*} p<0.05$.

${ }^{+} p<0.09$
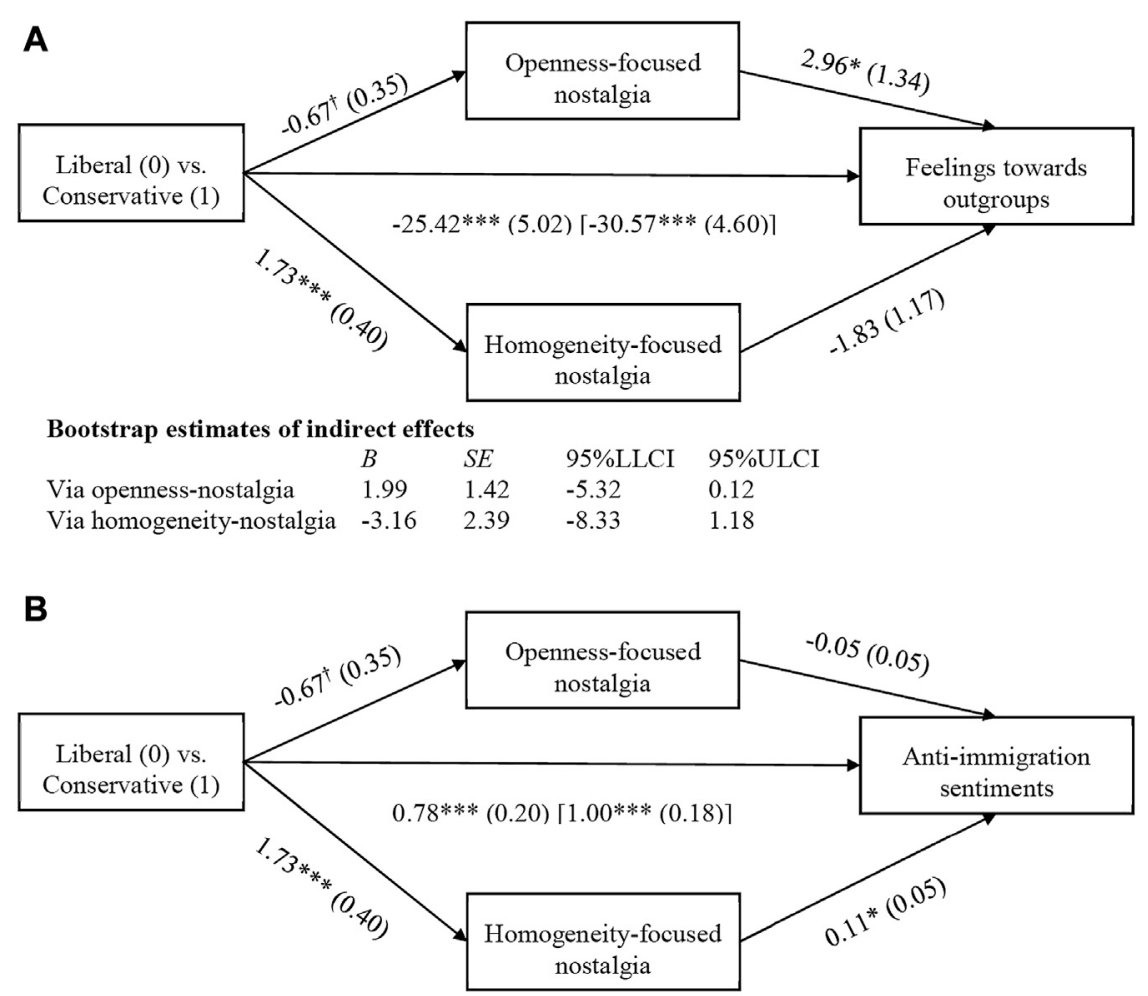

\begin{tabular}{lllll}
\multicolumn{2}{l}{ Bootstrap estimates of indirect effects } \\
& $B$ & $S E$ & $95 \% \mathrm{LLCI}$ & $95 \% \mathrm{ULCI}$ \\
Via openness-nostalgia & 0.03 & 0.05 & -0.04 & 0.14 \\
Via homogeneity-nostalgia & 0.19 & 0.11 & 0.01 & 0.42
\end{tabular}

FIGURE 2 | Mediation of the effect of participants' political orientation on (A) feelings towards outgroups and (B) social distance towards outgroups in study 2 (Canadian students). Unstandradized coefficients are presented, total effects is in square brackets.

Lastly, we conducted two mediation analyses (Process 3.0, Model 4; Hayes, 2017). In both analyses, we entered participants' political orientation as the independent variable, the two types of collective nostalgia as mediators, and the two measures of attitudes (feelings towards outgroups and anti-immigration sentiments) as the dependent variables. Conservatives were more likely than liberals to experience homogeneity-focused nostalgia, $B=1.72, S E=0.40,95 \% \mathrm{CI}[0.92,2.52]$, and marginally less likely than liberals to experience opennessfocused nostalgia, $B=-0.67, S E=0.35,95 \%$ CI $[-1.37,0.03]$. Openness-focused collective nostalgia related to more positive intergroup feelings, $B=2.96, S E=1.34,95 \% \mathrm{CI}[0.29,5.63]$, but homogeneity-focused collective nostalgia was unrelated to intergroup feelings, $B=-1.83, S E=1.17,95 \% \mathrm{CI}[-4.16,0.50]$. Although participants' political orientation was a significant and strong predictor of their intergroup feelings, $B=-30.57, S E=$ 
$4.60,95 \%$ CI $[-39.70,-21.43]$, this effect was not mediated by their openness-focused, $B=-1.99, S E=1.42,95 \% \mathrm{CI}[-5.32$, 0.12 ], or homogeneity-focused collective nostalgia, $B=-3.16, S E$ $=2.39,95 \%$ CI $[-8.33,1.18]$ (Figure 2A).

In the model for anti-immigration sentiments, the relations between participants' political orientation and both types of collective nostalgia were identical. Homogeneity-focused collective was a significant predictor of anti-immigration sentiments, $B=0.11, S E=0.05,95 \% \mathrm{CI}[0.01,0.20]$, whereas openness-focused collective nostalgia was not, $B=$ $-0.05, S D=0.05,95 \%$ CI $[-0.16,0.05]$, Again, participants political orientation was a significant predictor of their antiimmigration sentiments, $B=1.00, S E=0.18,95 \%$ CI $[0.63$, 1.37]. This effect was mediated by homogeneity focused collective nostalgia, $B=0.19, S E=0.11,95 \%$ CI $[0.01,0.42]$, but openness-focused collective nostalgia was not a significant mediator, $B=0.03, S E=0.05,95 \% \mathrm{CI}[-0.04,0.14]$ (Figure 2B).

\section{Discussion}

Study 2 replicated the main findings of Study 1, in that Study 2 demonstrated significant differences in the type of collective nostalgia reported by participants who identify as conservatives or liberals. Conservatives displayed significantly more homogeneity-focused nostalgia than liberals, an effect typically found in the collective nostalgia literature (Lammers and Baldwin, 2018). However, when openness-focused collective nostalgia was assessed, it was liberals who displayed (marginally) higher levels of this emotion. Additionally, homogeneity-focused collective nostalgia mediated the effect of conservative participants' political orientation on their anti-immigration sentiments. Although these effects were promising, Study 2 suffered from two shortcomings that may undermine the reliability of its findings. Due to recruitment difficulties, the sample size was much smaller than intended, rendering the study insufficiently powered to detect all effects of interest. Additionally, the sample was disproportionately liberal, which is typical of the student population (Hastie, 2007), but makes comparisons between conservatives and liberals less reliable. We decided to test the replicability of our findings in another study, conducted with a large online sample of English adults.

\section{Study 3 \\ Methods}

Similar to Study 2, Study 3 was embedded in a larger project on the effects of political change (i.e., parliamentary elections) on people's sense of collective continuity, nostalgia, and political attitudes. The study consisted of four measurement points, two before and two after the most recent British parliamentary election in November 2019. ${ }^{7}$ Data are available at OSF: https:// osf.io/u8hxv/

\footnotetext{
${ }^{7}$ Please note that there were no differences between participants who took part in the study at Time 1, Time 2, Time 3, and Time 4; and the pattern of results held whether Time 1 , Time 2 , Time 3 , or Time 4 results were analyzed.
}

\section{Participants}

Given that Study 3 used a longitudinal design with four measurement points, it had to account for projected attrition estimated at about $50 \%$ between each wave. Thus, to achieve a sample size of at least 200 at Time 4, we recruited 2,347 participants at Time $1 .{ }^{8} \mathrm{We}$ recruited participants and conducted the study using Qualtrics. The company recruited a large sample of online participants and followed them up over the course of the four study waves. Participants, who were British citizens residing in England, were on average 55.36 years old (SD = 13.32). Of them, $1,237(52.71 \%)$ identified as female, 1,109 $(47.25 \%)$ as male, and $1(0.04 \%)$ as transgender.

\section{Measures}

Study 3 measures were virtually identical to those of Study 2, with wording adjusted to the English context. ${ }^{9}$ The only exception was that we selected five minority groups most salient in Britain to measure participants' attitudes with a feeling thermometer. Unless otherwise indicated, all measures used a response scale ranging from 1 (strongly disagree) to 7 (strongly agree).

We assessed political orientation with a single item: "What is your political orientation?" ( 1 = very left wing, $2=$ moderately left wing, $3=$ center, $4=$ moderately right wing, $5=$ very right wing, $6=$ don't know/other. $)^{10}$ In line with the previous studies, we excluded participants who selected center and don't know/ other as their political preference, and created a binary variable that captured the split between left-leaning $(n=454)$ and right-leaning $(n=698)$ participants.

We measured collective nostalgia as in Study 2, two items tapping into homogeneity-focused nostalgia, $r(1149)=0.710, p<$ 0.001 , and two items tapping into openness-focused nostalgia, $r(1147)=0.803, p<0.001$ (after Wohl et al., 2020b). We averaged responses to create two composite scores.

We measured intergroup attitudes with a feeling thermometer towards outgroups and a measure of anti-immigration sentiments. The feeling thermometer asked about participants' feelings towards five groups: Muslims, refugees, Indians, Africans, and Poles $(-50=$ cold/negative,$+50=\mathrm{warm} /$ positive $)$. The items were strongly inter-correlated, and so we averaged responses to create an index of intergroup feelings $(\alpha=0.92)$. We measured anti-immigration sentiments with a single item: "The number of immigrants the British government is allowing into our country is ..." $(1=$ way too little, 5 = way too many $)$.

\footnotetext{
${ }^{8} \mathrm{~A}$ sensitivity power analysis indicated that the study was sufficiently powered to detect the crucial interaction of political orientation and type of collective nostalgia (achieved power $=0.87$ ), as well as the mediation effects (all achieved a power of 1.00).

${ }^{9}$ In Study 3, we used the same design as in Study 2. Also, Study 3 involved the same additional measures (besides the ones reported here) as part of the broader project (Footnote 6). The larger project (including the hypothesis about differences between conservatives and liberals in collective nostalgia content) was preregistered at OSF: https://osf.io/cqnpr/

${ }^{10}$ In the British context, we refer to right-wing versus left-wing rather than
} conservative versus liberal political orientation. 
TABLE 3 | Means, standard deviations, correlations among variables, and comparisons between liberals and conservatives study 3.

\begin{tabular}{|c|c|c|c|c|c|c|c|c|}
\hline & \multicolumn{2}{|c|}{$M(S D)$} & \multirow[t]{2}{*}{$F_{\text {int }} / t$} & \multirow[t]{2}{*}{$\eta_{p}^{2} / d$} & \multirow[t]{2}{*}{1.} & \multirow[t]{2}{*}{2.} & \multirow[t]{2}{*}{3.} & \multirow[t]{2}{*}{4.} \\
\hline & Right-wing & Left-wing & & & & & & \\
\hline 1. CN-homogeneity & $4.54(1.35)$ & $3.56(1.67)$ & $279.46^{\star \star \star}$ & 0.20 & & -0.016 & $-0.360^{\star \star \star}$ & $0.398^{\star \star \star}$ \\
\hline 2. CN-openness & $3.99(1.47)$ & $5.19(1.39)$ & & & $-0.217^{\star \star \star}$ & & $0.392^{3}$ & $-0.323^{* \star}$ \\
\hline 3. Attitudes & $-2.54(20.87)$ & $15.58(22.43)$ & $13.95^{\star \star \star}$ & -0.84 & $-0.399^{\star \star \star}$ & $0.481^{\star \star \star}$ & & $-0.549^{\star \star}$ \\
\hline 4. Anti-immigration & $4.08(0.84)$ & $3.20(0.95)$ & $-16.46^{\star \star \star}$ & 0.99 & $0.458^{\star \star \star}$ & $-0.438^{\star \star \star}$ & $-0.523^{\star \star \star}$ & \\
\hline
\end{tabular}

CN-homogeneity, homogeneity-focused collective nostalgia; CN-openness, Openness-focused collective nostalgia; Feelings, Feeling thermometer towards outgroups; Anti-immigration, anti-immigration sentiments. We calculated the comparison between levels of the two types of collective nostalgia between conservatives and liberals using mixed-design Analysis of Variance (ANOVA) $\left(F_{\text {int }}=\right.$ interaction term), and calculated the comparison for levels of feelings towards outgroups and social distance using independent sample $\mathrm{t}$-test. Means with the same superscript do not differ from one another. Correlations above the diagonal are for conservatives, below for liberals.

${ }^{* * *} p<0.001$.

\section{Results}

We followed the same data-analytic strategy as before. We present, in Table 3, means, standard deviations, correlations among variables, and differences between right-leaning and left-leaning participants on the measured variables. Again, homogeneityfocused collective nostalgia was significantly and negatively related to warm feelings towards outgroups and positively associated with anti-immigration sentiments, whereas an opposite pattern was true for openness-focused nostalgia. These relations held for people with self-declared right- and left-wing political preferences. The two types of collective nostalgia did not correlate among right-wing participants but were negatively related among left-wing participants.

Right-wing participants displayed significantly colder feelings towards outgroups and significantly stronger antiimmigration sentiments than left-wing participants. The interaction between participants' political orientation and the type of collective nostalgia they reported was significant, $F(1$, $1150)=279.18, p<0.001, \eta_{\mathrm{p}}{ }^{2}=0.20$. Left-wing participants declared significantly higher levels of openness-focused nostalgia than homogeneity-focused nostalgia $\left(p<0.001, \eta_{\mathrm{p}}{ }^{2}\right.$ $=0.18)$, whereas right-wing participants evinced the reverse pattern $\left(p<0.001, \eta_{\mathrm{p}}{ }^{2}=0.04\right)$. Left-wing participants' opennessfocused nostalgia was stronger than the same emotion among right-wing participants $\left(p<0.001, \eta_{\mathrm{p}}{ }^{2}=0.14\right)$, whereas homogeneity-focused nostalgia was stronger among rightwing participants, compared to left-wing participants $(p<$ $0.001, \eta_{\mathrm{p}}{ }^{2}=0$ 0.10). Similarly to Study 1 , the overall difference in the level of collective nostalgia between rightwing and left-wing participants was not significant, $F(1,1150)=$ $3.57, p=0.059, \eta_{\mathrm{p}}{ }^{2}=0.003$.

We proceeded with two mediation models (Process 3.0, Model 4; Hayes, 2017). In both models, we entered participants' political orientation ( 1 = right-wing, $0=$ left-wing) as the independent variable, the two types of collective nostalgia as mediators, and the two measures of intergroup attitudes as separate dependent variables. Right-wing participants had higher levels of homogeneity-focused nostalgia, $B=0.99, S E=0.09$, 95\%CI $[0.81,1.17]$, and lower levels of openness-focused nostalgia, $B=-1.21, S E=0.09,95 \% \mathrm{CI}[-1.38,-1.04]$. Participants' right-wing political orientation, $B=-6.33, S E=1.23,95 \% \mathrm{CI}$ $[-8.73,-3.92]$, as well as homogeneity-focused nostalgia, $B=$ $-4.76, S E=0.37,95 \% \mathrm{CI}[-5.47,-4.05]$, were negative predictors of warm feelings towards outgroups, whereas openness-focused nostalgia was a positive predictor, $B=5.86, S E=0.37,95 \% \mathrm{CI}$ $[5.13,6.59]$. Both homogeneity-focused nostalgia, $B=-4.71, S E=$ $0.60,95 \%$ CI $[-5.92,-3.58]$, and openness-focused nostalgia, $B=$ $-7.08, S E=0.74,95 \% \mathrm{CI}[-8.58,-5.70]$, emerged as significant mediators of the effect of political orientation of feelings towards outgroups (Figure 3A).

In the model for anti-immigration sentiments (Figure 3B), political orientation was a positive predictor of the dependent variable, $B=0.40, S E=0.05,95 \% \mathrm{CI}[0.31,0.50]$, as was homogeneity-focused collective nostalgia, $B=0.23, S E=0.01$, $95 \%$ CI $[0.20,0.26]$. Openness-focused collective nostalgia emerged as a significant negative predictor of anti-immigration sentiments, $B=-0.20, S E=0.02,95 \%$ CI [ $-0.23,-0.17]$. Both homogeneity-focused nostalgia, $B=0.23, S E=0.03,95 \% \mathrm{CI}[0.18$, 0.28 ], and openness-focused nostalgia, $B=0.25, S E=0.03,95 \% \mathrm{CI}$ $[0.19,0.30]$, were significant mediators of the effect of political orientation on anti-immigration sentiments.

\section{Discussion}

Study 3 replicated the effects of the two previous studies, using a large sample of participants recruited in a different cultural context. Political orientation significantly predicted participants' homogeneity- and openness-focused collective nostalgia. Participants who identified as right-wing showed higher levels of collective nostalgia, but only when the object of nostalgia was the homogenous society of the past. The reverse was true for openness-focused nostalgia-it was left-wing participants who displayed significantly stronger nostalgia of this type, as compared to right-wing participants. Both types of collective nostalgia mediated the effect of right-wing (vs. leftwing) political orientation on more negative feelings towards outgroups and anti-immigration sentiments.

\section{GENERAL DISCUSSION}

In line with our general hypothesis, across three studies in three national contexts (the United States, Canada, and England), we demonstrated that people who identify as conservatives (rightwing) and liberals (left-wing) report experiencing different types of collective nostalgia. Across all studies, conservatives scored significantly higher than liberals on a measure of collective 

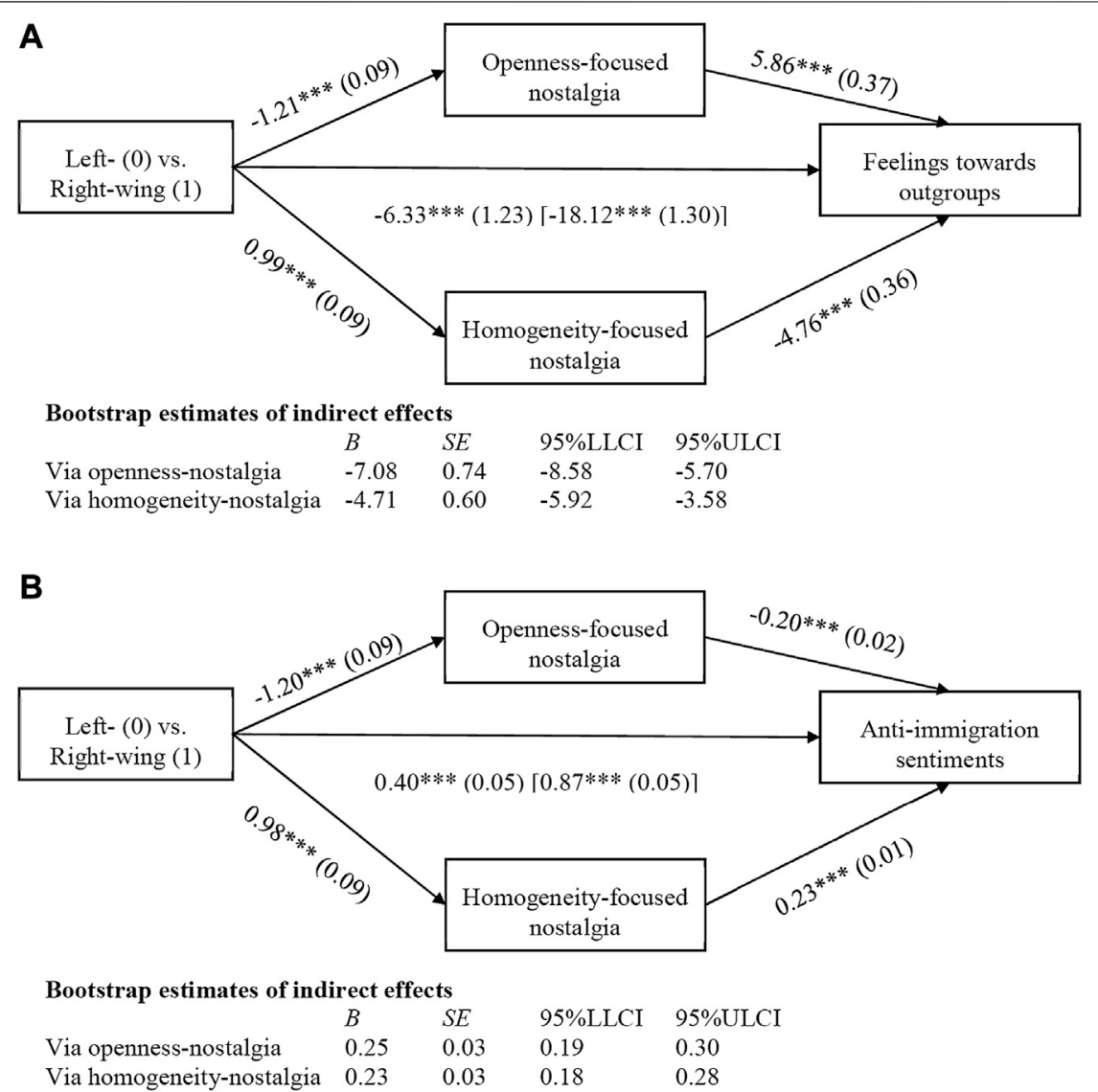

FIGURE 3 | Mediation of the effect of participants' political orientation on (A) feelings towards outgroups and (B) social distance towards outgroups in study 1 (British participants, Qualtries panel). Unstandradized coefficients are presented, total effects is in square brackets.

nostalgia for a more homogenous society. However, liberals reported experiencing significantly more collective nostalgia for an open society of the past compared to conservatives. Greater nostalgia for a homogenous society and decreased nostalgia for an open society, partially explained the relation between participants' conservative (vs. liberal) political orientation and their negative intergroup attitudes, which we measured with a feeling thermometer (Studies 1-3), social distance scale (Study 1), and an anti-immigration sentiments item (Studies 2 and 3).

This work contributes to the literature in several ways. First and foremost, it provides evidence for the existence of "liberal" collective nostalgia. In this way, the work extends previous research that suggested collective nostalgia is an intrinsically conservative emotion-an emotion responsible for increased support for right-wing populism worldwide (Kenny, 2017; Lammers and Baldwin, 2018). Granted, when we collapsed across different types of collective nostalgia, we found equivalent levels of collective nostalgia among conservatives and liberals in two out of three studies (in Study 2, conservatives scored marginally higher than liberals, but the study was underpowered and the observed difference small). Importantly, though, we showed that people who identify as liberals reported more collective nostalgia than conservatives when the measure of collective nostalgia was oriented to a past that resonates with liberal-oriented sentiments (i.e., openness to other cultures and traditions).

Second, our findings contribute to a growing literature that provides a more nuanced understanding of emotions by focusing on their specific experience and contents. For instance, a distinction between benign and malicious envy allowed for a better understanding of positive (a desire to improve) and negative (a desire to pull down those who are better) outcomes of envy (Lange and Crusius, 2015). Similarly, a meta-analysis on the effects of shame showed that, whereas this emotion is typically associated with avoidance orientation (e.g., avoiding the domain in which one failed), sometimes it is also associated with approach orientation (e.g., selfimprovement). Whether one or the other prevailed depended on people's perception of their failure as repairable or not (Leach and Cidam, 2015). In a similar vein, our findings suggest that, once the content of collective nostalgia is taken into account, we can better understand the link between people's political orientation and their nostalgic experiences. Conservatives are not necessarily the only ones to experience collective nostalgia. Rather, they seemed more nostalgic, because most measures of collective nostalgia employed in the literature did not differentiate 
the content of this emotion. Replicating previous findings (Kenny, 2017; Wohl et al., 2020c), the two types of collective nostalgia investigated herein were also differentially related to intergroup outcomes. Whereas collective nostalgia for a homogenous society was a negative predictor of warm feelings towards and acceptance of outgroups, collective nostalgia for an open society showed the reverse pattern of associations.

Third, our work reframes traditional understanding about conservative compared to liberal philosophy. In particular, results across the three studies suggest that positioning conservative thought as being primarily backward-looking and liberal thought as being primarily forward thinking may be simplistic (see also Robinson, 2016; Kenny, 2017). Both conservatives and liberals may experience the changes occurring in the modern world as negative or threatening (Wohl et al., 2020a). The key difference between them is not that conservatives seek refuge from negatively evaluated present by looking to the past, whereas liberals look to the future, but that they focus on different elements of the past (and likely the future). A group's history constitutes a reservoir of different elements (events, social trends, characters) that can be selectively brought to mind as a function of group members' current needs and goals (Sammut et al., 2015). Political ideology, understood as a set of beliefs about how society should be organized and how the proper organization may be achieved (Erikson and Tedin, 2003; Jost et al., 2008), is an important factor shaping the ways in which people perceive their group's present and the elements of the group's past that inspire their nostalgia.

\section{Limitations and Future Directions}

The presented research is not without limitations. First, all three studies are correlational, thus precluding causal inferences. Past research shows that it is possible to manipulate collective nostalgia (Wildschut et al., 2014; Wohl et al., 2020b; Lammers and Baldwin, 2020). Thus, we hope that future studies will experimentally manipulate collective nostalgia that resonates (vs. not) with people's political orientation and investigate its effects on intergroup attitudes but also other outcomes, such as political candidate support, policy support, and political behavior.

Second, as research on collective nostalgia contents is in its infancy, we focused on just two distinct types of collective nostalgia. This does not mean that these are the only two types of nostalgia that exists. Arguments from liberal politicians (e.g., Bernie Sanders) as well as political scientists (e.g., Mudde, 2017) point to nostalgia for the welfare state and stronger working class of the past. In times of economic crisis, such as the current pandemic-related downturn, people may feel nostalgic for times of relative prosperity, while members of currently dominant racial groups may feel nostalgic for their greater power in times of racial demographic shift. Future research should address the additional types of nostalgic content, as well as their correlates and consequences for present day political attitudes and behavior.

Third, we acknowledge some methodological shortcomings. Due to space and resource constraints, we used short, and even one-item, measures to tap into concepts of interest (e.g., the one-item measure of anti-immigration sentiments in Studies 2 and 3). Ideally, future research would use longer and multifaceted measures to assess more comprehensively these constructs. Our studies were conducted with convenience samples, not representative of their respective populations. However, the external validity of the presented results is somewhat strengthened by results reported by Clifford et al. (2015) who showed that liberals and conservatives on MTurk closely resemble their offline counterparts. Additionally, Study 2's sample was also smaller than intended (due to recruitment difficulties), which resulted in low power to detect the mediation effects and providing somewhat weaker evidence than the other two studies. Despite that, all studies were sufficiently powered to detect the interaction of political orientation and the type of nostalgia reported.

\section{CONCLUSION}

Across three studies, we showed that collective nostalgia is not the sole domain of conservatism. Although it is true that conservatives are apt to nostalgize, so too are liberals; they simply long for a different (perceived) time in their group's history. Conservatives nostalgize about a time when the group was more homogeneous, whereas liberals nostalgize about a time when the group was more open to the culture and traditions of other groups. These results are in contrast to established schools of political thought that frame conservatism as focused on maintaining the status quo (i.e., adherence to the values of the past), and liberalism as focused on moving the group forward (i.e., advancing and reformation of group values). For a fuller understanding of why conservatives (compared to liberals) are less accepting of outgroup members, it is important to take into account the stories conservatives and liberals tell about their group's past. The stories are not told for mere entertainment. They are functional in that they convey group values and the group's essence. When group members believe that essence is under threat, they will look to the past-a past when the ingroup was on more solid ground. For conservatives, solid ground is represented by a time when diversity was less prevalent. A consequence is the desire to shield the ingroup from outgroups. For liberals, solid ground is represented by a time when acceptance of other cultures was more prevalent, which motivates the desire to embrace outgroups. In short, emotional ties to the group's past matter for understanding present-day political divides.

\section{DATA AVAILABILITY STATEMENT}

The datasets presented in this study can be found in online repositories. The names of the repository/repositories and accession numbers can be found below: Center for Open Science. Study 1: https://osf.io/vutyq/ Study 2: https://osf.io/ vga8c/ Study 3: https://osf.io/u8hxv/.

\section{ETHICS STATEMENT}

The studies involving human participants were reviewed and approved by the Carleton University Office of Research Ethics. 
Written informed consent for participation was not required for this study in accordance with the national legislation and the institutional requirements.

\section{AUTHOR CONTRIBUTIONS}

All authors were involved in designing the theoretical framework of this work. ASt and MW designed and conducted Studies 1 and 2 , all authors were involved in the design and data collection of Study 3. ASt analyzed the results, ASt and MW wrote the manuscript, all authors contributed to the revision.

\section{REFERENCES}

Anspach, C. K. (1934). Medical dissertation on nostalgia by Johannes Hofer, 1688. Bull. Inst. Hist. Med. 2, 376-391.

Bilewicz, M., Winiewski, M., Kofta, M., and Wójcik, A. (2013). Harmful ideas, the structure and consequences of anti-semitic beliefs in Poland. Polit. Psychol. 34, 821-839. doi:10.1111/pops.12024

Cheung, W. Y., Hepper, E. G., Reid, C. A., Green, J. D., Wildschut, T., and Sedikides, C. (2020). Anticipated nostalgia: looking forward to looking back. Cogn. Emot. 34, 511-525. doi:10.1080/02699931.2019.1649247

Clifford, S., Jewell, R. M., and Waggoner, P. D. (2015). Are samples drawn from Mechanical Turk valid. for research on political ideology? Res. Politics 2 (4), 2053168015622072

Duckitt, J. (2001). A dual-process cognitive-motivational theory of ideology and prejudice. Adv. Exp. Soc. Psychol. 33, 41-113. doi:10.1016/S0065-2601(01) 80004-6

Duyvendak, J. (2011). The politics of home: nostalgia and belonging in western europe and the United States. Int. J. Hous. Policy 12, 250-252. doi:10.1080/ 14616718.2012.681559

Erikson, R. S., and Tedin, K. L. (2003). American public opinion: its origins, content, and impact. New York, NY: Longman, 398.

Gaston, S., and Hilhorst, S. (2018). Nostalgia as a cultural and political force in Britain, France and Germany. London, United Kingdom: DEMOS, 341.

Hastie, B. (2007). Higher education and sociopolitical orientation: the role of social influence in the liberalisation of students. Eur. J. Psychol. Educ. 22, 259-274. doi:10.1007/BF03173425

Hayes, A. F. (2017). Introduction to mediation, moderation, and conditional process analysis: a regression-based approach. MS dissertation. New York (NY): Guilford publications.

Holbrook, M. B. (1993). Nostalgia and consumption preferences: some emerging patterns of consumer tastes. J. Consum. Res. 20, 245-256. doi:10.1086/209346

Jacobs, T. (2018). Conservatives' love of nostalgia can be used to promote liberal values. Pac. Stand. Available at: https://psmag.com/news/the-grand-old-partylongs-for-the-good-old-days (Accessed November 24, 2020).

Jetten, J., and Wohl, M. J. A. (2012). The past as a determinant of the present: historical continuity, collective angst, and opposition to immigration. Eur. J. Soc. Psychol. 42, 442-450. doi:10.1002/ejsp.865

Jost, J. T., Federico, C. M., and Napier, J. L. (2008). Political ideology: its structure, functions, and elective affinities. Annu. Rev. Psychol. 60, 307-337. doi:10.1146/ annurev.psych.60.110707.163600

Jost, J. T., Glaser, J., Kruglanski, A. W., and Sulloway, F. J. (2003). Political conservatism as motivated social cognition. Psychol. Bull 129, 339-375. doi:10. 1037/0033-2909.129.3.339

Kenny, M. (2017). Back to the populist future?: understanding nostalgia in contemporary ideological discourse. J. Polit. Ideol. 22, 256-273. doi:10.1080/ 13569317.2017.1346773

Kirk, R. (1953). The conservative mind: from Burke to Eliot. New York, NY: Avon Books.

Lammers, J., and Baldwin, M. (2018). Past-focused temporal communication overcomes conservatives resistance to liberal political ideas. J. Pers. Soc. Psychol. 114, 599-619. doi:10.1037/pspi0000121

\section{FUNDING}

This research was supported by the Social Sciences and Humanities Research Council of Canada Insight Grant (\#435-2019-0692) to Wohl.

\section{SUPPLEMENTARY MATERIAL}

The Supplementary Material for this article can be found online at: https://www.frontiersin.org/articles/10.3389/fpos.2021.633688/ full\#supplementary-material.

Lammers, J., and Baldwin, M. (2020). Make America gracious again: collective nostalgia can increase and decrease support for right-wing populist rhetoric. Eur. J. Soc. Psychol. 50, 943-954. doi:10.1002/ejsp.2673

Lange, J., and Crusius, J. (2015). Dispositional envy revisited: unraveling the motivational dynamics of benign and malicious envy. Pers Soc. Psychol. Bull. 41, 284doi:10.1177/0146167214564959

Leach, C. W., and Cidam, A. (2015). When is shame linked to constructive approach orientation? A meta-analysis. J. Pers Soc. Psychol. 109, 983. doi:10.1037/pspa0000037

Leunissen, J., Wildschut, T., Sedikides, C., and Routledge, C. (2020). The hedonic character of nostalgia: an integrative data analysis. Emot. Rev. 1754073920950455, 175407392095045. doi:10.1177/1754073920950455

Mudde, C. (2016). On extremism and democracy in Europe. London, England: Routledge.

Mudde, C. (2018). The far right in America London, England: Routledge.

Mudde, C., and Kaltwasser, C. R. (2018). Studying populism in comparative perspective: reflections on the contemporary and future research agenda. Comp. Polit. Stud. 51, 27. doi:10.1177/0010414018789490

Mudde, C. (2017). The far right in America. London, United Kingdom: Routledge, 146.

Muller, J. Z. (1997). Conservatism: an anthology of social and political thought from David Hume to the present. Princeton, NJ: Princeton University Press.

Remarks by the President on Comprehensive Immigration Reform (2013). Whitehouse.gov. Available at: https://obamawhitehouse.archives.gov/the-pressoffice/2013/01/29/remarks-president-comprehensive-immigration-reform (Accessed November 24, 2020).

Robinson, E. (2016). Radical nostalgia, progressive patriotism and labour's "English problem". Polit. Stud. Rev. 14, 378-387. doi:10.1177/1478929916649613

Sammut, G., Andreouli, E., Gaskell, G., and Valsiner, J. (2015). The cambridge handbook of social representations. Cambridge, United Kingdom: Cambridge University Press, 481.

Sani, F. (2010). Self Continuity: individual and collective perspectives. New York, NY: Psychology Press, 289.

Schlesinger, A. (1955). The new conservatism: politics of nostalgia. The Reporter $16,9-11$.

Sedikides, C., Wildschut, T., and Baden, D. (2004). "Nostalgia: conceptual issues and existential functions," in Handbook of experimental existential psychology. New York, NY: Guilford Press, 200-214.

Sedikides, C., and Wildschut, T. (2016). "Nostalgia: a bittersweet emotion that confers psychological health benefits," in The wiley handbook of positive clinical psychology. Editors A. M. Wood and J. Johnson (Chichester, United Kingdom: John Wiley \& Sons, Ltd), 125-136.

Sedikides, C., and Wildschut, T. (2019). The sociality of personal and collective nostalgia Eur. Rev. Soc. Psychol. 30, 123-173. doi:10.1080/10463283.2019.1630098

Smeekes, A., Verkuyten, M., and Martinovic, B. (2015). Longing for the country's good old days: national nostalgia, autochthony beliefs, and opposition to Muslim expressive rights. Br. J. Soc. Psychol. 54, 561-580. doi:10.1111/bjso.12097

Smeekes, A., and Verkuyten, M. (2015). The presence of the past: identity continuity and group dynamics. Eur. Rev. Soc. Psychol. 26, 162-202. doi:10. 1080/10463283.2015.1112653

Social Progress Index Executive Summary (2020). Social progress initiative Available at: https://www.socialprogress.org/index/global/results (Accessed January 15, 2021).

Wildschut, T., Bruder, M., Robertson, S., van Tilburg, W., and Sedikides, C. (2014). Collective nostalgia: a group-level emotion that confers unique 
benefits on the group. J. Pers. Soc. Psychol. 107, 844-863. doi:10.1037/ a0037760

Wohl, M. J. A., Stefaniak, A., and Smeekes, A. (2020a). Days of future past: concerns for the group's future prompt longing for its past (and ways to reclaim it). Curr. Dir. Psychol. Sci. 29, 1-6. doi:10.1177/0963721420924766

Wohl, M. J. A., Stefaniak, A., and Smeekes, A. (2020b). Longing is in the memory of the beholder: collective nostalgia content determines the method members will support to make their group great again. J. Exp. Soc. Psychol. 91, 104044. doi:10. 1016/j.jesp.2020.104044

Wohl, M. J. A., Stefaniak, A., and Smeekes, A. (2020c). Longing is in the memory of the beholder: collective nostalgia content determines the method members will support to make their group great again. J. Exp. Soc. Psychol. 91, 104044. doi:10. 1016/j.jesp.2020.104044

Wohl, M. J. A., and Stefaniak, A. (2020). "Collective nostalgia and the desire to make one's group great again," in Applications of social psychology: how social psychology can contribute to the solution of real-world problems Sydney symposium of social psychology, Visegrad, Hungary, July 8-12, 2019 (New York, NY: Routledge), 292-311.

Conflict of Interest: The authors declare that the research was conducted in the absence of any commercial or financial relationships that could be construed as a potential conflict of interest.

Copyright (๑) 2021 Stefaniak, Wohl, Sedikides, Smeekes and Wildschut. This is an open-access article distributed under the terms of the Creative Commons Attribution License (CC BY). The use, distribution or reproduction in other forums is permitted, provided the original author(s) and the copyright owner(s) are credited and that the original publication in this journal is cited, in accordance with accepted academic practice. No use, distribution or reproduction is permitted which does not comply with these terms. 